\title{
Social Media for Education on Mobile: A Case Study of College of Arts, Media and Technology, Thailand
}

\author{
Jenjira Jaimunk and Pradorn Sureephong
}

\begin{abstract}
The purpose of this work is investigation on utilizing social media to facilitate user interaction and support academic activities. Various social media are integrated which are video-sharing, location-based mapping, social networking, official site, and weather forecast. A case study of College of Arts, Media and Technology (CAMT), Chiang Mai University is conducted to actualize the proposed model on mobile. The implemented prototype provides a number of benefits for CAMT and other similar faculties as well.
\end{abstract}

Index Terms-Student community, mobile application, iPhone application, iOS, iOS application, social media, education.

\section{INTRODUCTION}

At the present moment, a large number of people use social media widely. Shea Bennett said that 684,478 contents are posed on Facebook and 48 hours of video are broadcasted to YouTube. [1] Socialbakers.com shows that there are 18,202,320 Facebook user accounts in Thailand that continuously grew to $11.83 \%$ from last 6 months. It is thirteenth of the world ranking and takes $27.13 \%$ of penetration by population as shown in Fig. 1. [2] Therefore, many organizations are concerning in announcing news and activities using these channels.

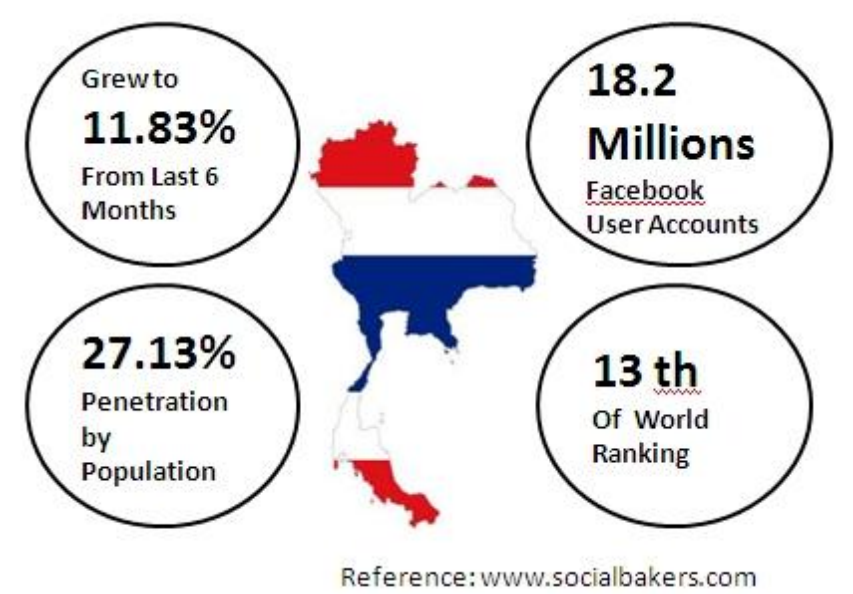

Fig. 1. Social network statistic- Thailand 2013

Although there are various social media available to facilitate user interaction, each tool has its outstanding characteristic i.e. social media supports user interaction and community, video-sharing allows user to upload and share

Manuscript received February 27, 2013; revised April 25, 2013.

The authors are with the Department of Software Engineering, College of Arts, Media and Technology, Chiang Mai University, Thailand (e-mail: janjira.se@gmail.com,dorn@ camt.info). their video content [3], and etc. The research aims to develop the social media on mobile that utilize the ability of many social media and mobile technology altogether to support educational activity and social interaction for students, alumni, academic staff, future student, and firm. For instant, using the social media to enhance the communication of user and allow sharing their contents, deploying video tutorial for supporting self-study of students, and emulating the idea market to increase the employment opportunity.

This paper is divided into 7 parts and organized as follow. Section II describes the literature review. The proposed framework is discussed on Section III. System architecture and prototype implementation are explained in Section IV and $\mathrm{V}$ respectively. Section VI projects benefits and conclusion is provided in section VII.

\section{LITERATURE REVIEW}

\section{A. Social Media}

There are a lot of social media definitions. Schlicht Patricia summarizes the definition of social media as it is the web based system that allows people to create their own profiles and share with their connected friends [4].

Nick Winchester defines social media are online media with 5 characteristics- participation, openness, conversation, community, and connectedness [5].

South Western Sydney Institute explains social networks as tools that allow user to create and share content easier, to promote user collaboration, and to create online communities that share the same interests [6].

In my opinion, social network is about sharing, interaction, and community. To share idea, profile, and contents, to interact with connected people, and to create community.

\section{B. Statistic of Social Network and Mobile Technology}

Holly Richmond presents that the desktop internet usage is conjectured to catch up by mobile internet usage on 2014 . Moreover, she said that social access for mobile internet usage is $91 \%$ and desktop is $79 \%$ [7].

Based on statistic mentioned above, it implies changing in behavior of the user. Users tend to join social media using mobile internet instead of desktop internet.

This study aims to migrate desktop application to mobile application by integrating social media and mobile service together.

\section{Features of University Application on Mobile}

The review of university application on mobile is collected in Table I. considering the following features of 
them, there are a number of features are included in the application such as map, news, events, video, photos, social, and so on. The rest of this article is designed to discuss on how to integrate these features to support the educational use.

TABLE I: THE REVIEW FOR FEATURES OF UNIVERSITY APPLICATION ON MOBILE

\begin{tabular}{|c|c|c|c|c|c|c|c|c|c|c|c|}
\hline \multirow{2}{*}{ Feature } & \multicolumn{11}{|c|}{ OXON University } \\
\hline & $\mathrm{HU}$ & $\mathrm{SU}$ & $\mathrm{YU}$ & $\mathrm{UC}$ & OXON & CMU & SJU & UVA & MIT & York U & ISE \\
\hline People/Directory & $\sqrt{ }$ & $\sqrt{ }$ & $\sqrt{ }$ & - & $\sqrt{ }$ & - & - & $\sqrt{ }$ & $\sqrt{ }$ & - & - \\
\hline Map & $\sqrt{ }$ & $\sqrt{ }$ & $\sqrt{ }$ & $\sqrt{ }$ & $\sqrt{ }$ & $\sqrt{ }$ & $\sqrt{ }$ & $\sqrt{ }$ & $\sqrt{ }$ & $\sqrt{ }$ & $\sqrt{ }$ \\
\hline Admissions & $\sqrt{ }$ & - & - & - & - & - & - & $\sqrt{ }$ & - & - & - \\
\hline Courses & $\sqrt{ }$ & $\sqrt{ }$ & - & - & - & - & $\sqrt{ }$ & $\sqrt{ }$ & - & $\sqrt{ }$ & - \\
\hline Transport & $\sqrt{ }$ & - & $\sqrt{ }$ & - & $\sqrt{ }$ & - & - & - & $\sqrt{ }$ & - & - \\
\hline Athletics & $\sqrt{ }$ & $\sqrt{ }$ & $\sqrt{ }$ & - & - & $\sqrt{ }$ & $\sqrt{ }$ & $\sqrt{ }$ & - & - & - \\
\hline Library & $\sqrt{ }$ & - & - & $\sqrt{ }$ & $\sqrt{ }$ & - & - & $\sqrt{ }$ & $\sqrt{ }$ & $\sqrt{ }$ & - \\
\hline News & $\sqrt{ }$ & $\sqrt{ }$ & $\sqrt{ }$ & $\sqrt{ }$ & $\sqrt{ }$ & $\sqrt{ }$ & $\sqrt{ }$ & $\sqrt{ }$ & $\sqrt{ }$ & $\sqrt{ }$ & $\sqrt{ }$ \\
\hline Events & $\sqrt{ }$ & $\sqrt{ }$ & $\sqrt{ }$ & $\sqrt{ }$ & - & $\sqrt{ }$ & $\sqrt{ }$ & $\sqrt{ }$ & $\sqrt{ }$ & $\sqrt{ }$ & - \\
\hline Video & $\sqrt{ }$ & - & $\sqrt{ }$ & $\sqrt{ }$ & - & $\sqrt{ }$ & $\sqrt{ }$ & $\sqrt{ }$ & - & - & $\sqrt{ }$ \\
\hline Photos & $\sqrt{ }$ & $\sqrt{ }$ & $\sqrt{ }$ & - & - & $\sqrt{ }$ & $\sqrt{ }$ & $\sqrt{ }$ & - & - & $\sqrt{ }$ \\
\hline $\begin{array}{l}\text { Social (Youtube, Twister, } \\
\text { Facebook, etc.) }\end{array}$ & $\sqrt{ }$ & $\sqrt{ }$ & - & - & - & $\sqrt{ }$ & $\sqrt{ }$ & - & - & - & $\sqrt{ }$ \\
\hline Alert & $\sqrt{ }$ & - & - & - & - & - & - & $\sqrt{ }$ & - & - & - \\
\hline About & $\sqrt{ }$ & - & - & - & - & - & - & - & - & $\sqrt{ }$ & $\sqrt{ }$ \\
\hline Radio & - & $\sqrt{ }$ & - & - & $\sqrt{ }$ & $\sqrt{ }$ & - & - & - & - & - \\
\hline Weather & - & - & - & - & $\sqrt{ }$ & $\sqrt{ }$ & - & - & - & - & - \\
\hline Exam result & - & - & - & - & $\sqrt{ }$ & - & - & - & - & $\sqrt{ }$ & - \\
\hline Academic Calendar & - & - & - & - & $\sqrt{ }$ & - & - & $\sqrt{ }$ & - & - & - \\
\hline Polls & - & - & - & - & - & $\sqrt{ }$ & $\sqrt{ }$ & - & - & - & - \\
\hline Emergency info. & - & - & - & - & - & $\sqrt{ }$ & - & $\sqrt{ }$ & $\sqrt{ }$ & - & - \\
\hline
\end{tabular}

$\mathrm{HU}=$ Harvard University

$\mathrm{SU}=$ Stanford University

$\mathrm{YU}=$ Yale University

UC = University of Cambridge

Oxon $=$ University of Oxford

$\mathrm{CMU}=$ Central Michigan University

$\mathrm{SJU}=$ St. John's University

UVA = University of Virginia

MIT = Massachusetts Institute of Technology

York $\mathrm{U}=$ York University

ISE = International School of Engineering, Faculty of Engineering, Chulalongkorn university 


\section{PROPOSED FRAMEWORK}

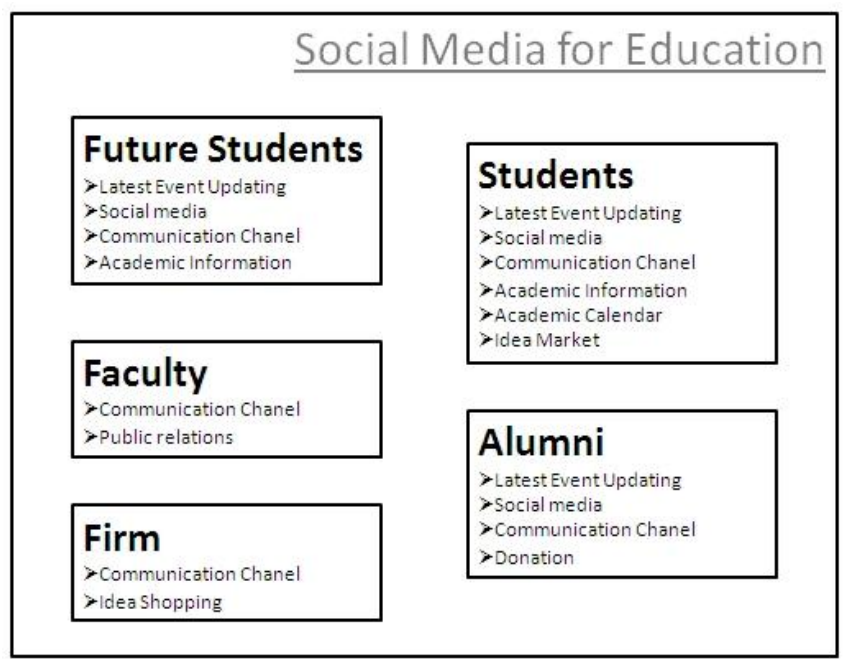

Fig. 2. Proposed framework of social media for education

The proposed framework contains 5 modules that based on users. They are future students, students, college, alumni, and firm. Each module comprises a number of necessary media to facilitate user's function and activities.

\section{A. Future Students}

Future students are who expect to study in this faculty. They obtain all news feed and latest updated event from faculty using application. They can send message to another user using service from social media service provider and other communication channel such as email. By using social media for education system, they also can achieve the academic information.

\section{B. Students}

The social media for education supports both communication and academic activities to current students. For example, student can update news and events and access to academic calendar easier. The application provides idea market to students where they can present their work pieces to firm. Moreover, students can self-study using video tutorial. The communication channels are offered to facilitate social interaction between students themselves and students and faculty.

\section{Alumni}

Alumni acquire news feed and latest activities from faculty. The several of communication channels are available where alumni can connect with faculty easier.

\section{Faculty}

Faculty (or in this paper is College of Arts, Media and Technology- CAMT) has 2 communication directions to application which are providing content to application i.e. curriculum information and receive message from application such as student's feedback.

By using this social media for education on mobile, the faculty can share out the academic information to future student, news and latest activities to all other users. The communication channels are enhanced using available social media and other mobile services.

\section{E. Firm}

Firms can shop ideas of students on idea market. The social media for education supports firm in communication with faculty or student by social networking and videosharing service.

\section{SyStEM ARCHITECTURE}

System Architecture of social media for education on mobile composes of 3 layers which are user layer, application layer, and content layer. The application layer is the layer between user layer and content layer. The user layer communicates with application layer using mobile. The application layer accesses content layer via network.

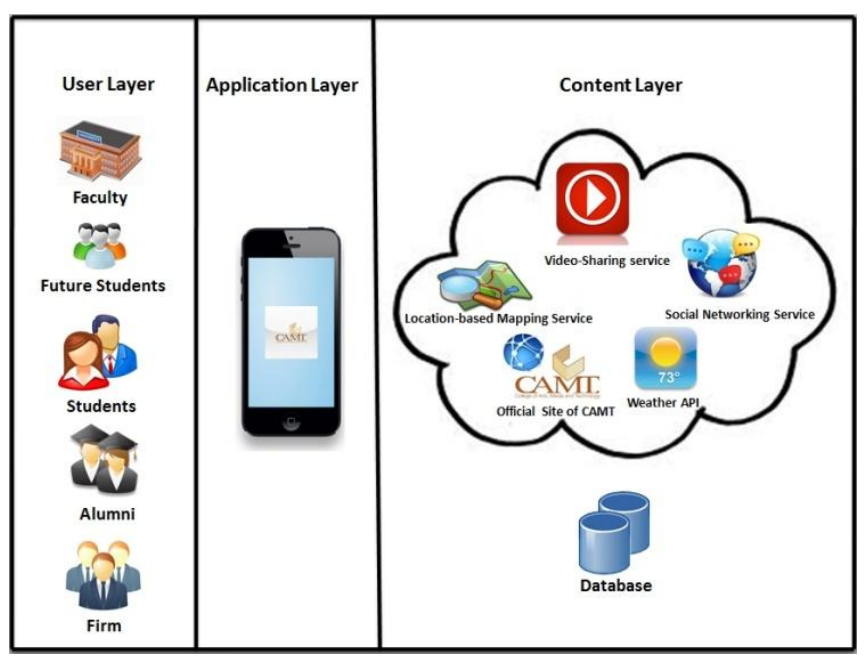

Fig. 3. System architecture of social media for education

\section{A. User Layer}

User layer is the content consumer. User layer accesses contents by sending request to application layer.

User layer for this system contains 5 types those are faculty, future student, students, alumni, and firm.

\section{B. Application Layer}

The application layer deals with implementing user requests and return result based on user input data.

When user request for content, the application layer will execute request by connecting to content layer via internet connection. It translates content and displays them on the users' screen.

\section{Content Layer}

The content layer is the layer that obtains and handles content to application. There are 2 main kinds of content in the content layer which are contents on cloud and embedded database. The contents on cloud are contents that provided by service provider which are video-sharing, location-based mapping, social networking, official site, and weather forecast.

Academic data is stored on database. It is embedded with the application on mobile. The academic data is display on academic calendar covering academic events and its detail. 


\section{PROTOTYPE IMPLEMENTATION}
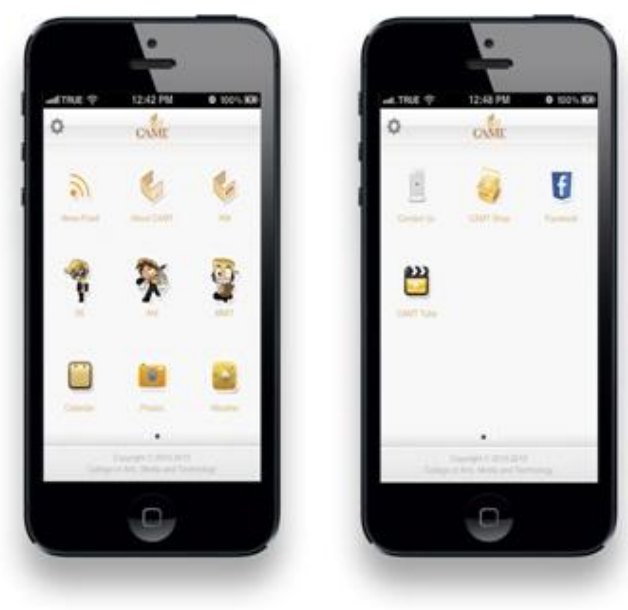

Fig. 4. User interface of implemented prototype

\section{A. Academic Information}

Academic information contains detail of College of Arts, Media and Technology (CAMT), Knowledge Management (KM), Software Engineering (SE), Animation (ANI), and Modern Management and Information Technology (MMIT), provides the available courses and description for each course including philosophy, curriculum structure, qualification of apply and requirement for admission, fee, career opportunities, and student activities. This information is useful for future students who expect to study in the faculty.

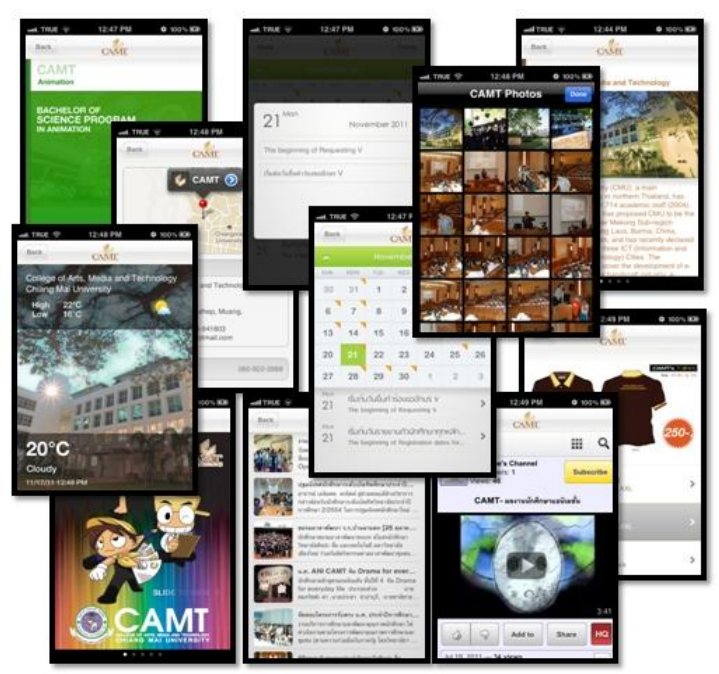

Fig. 5. Features of social media for education

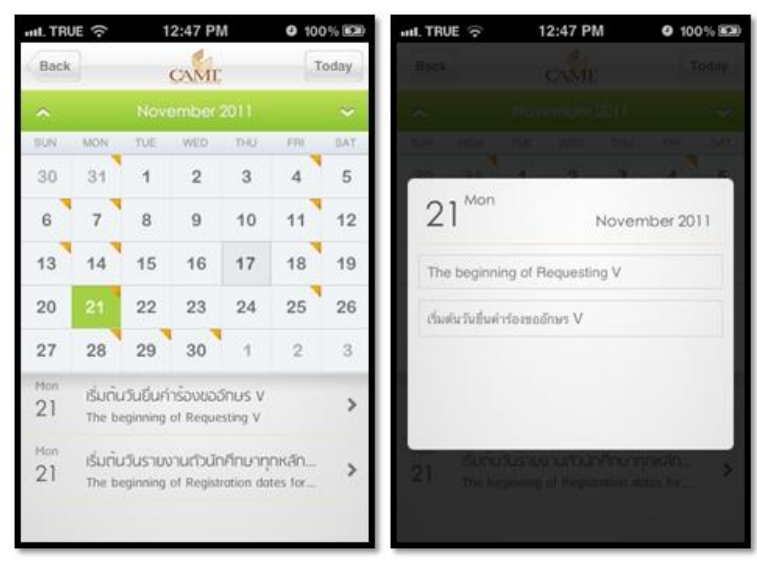

Fig. 6. Academic calendar

\section{B. Academic Calendar}

Academic calendar handles academic events and its detail to students and academic staffs. It's very important to students and academic staffs to check for important dates for example enrollment date, examination date, term begins date, and so on.

The contents of academic calendar are organized as Fig. 6. The important dates are pinned with yellow points. When user clicks on the important date, the detail of that date will be displayed both in Thai and English language.

\section{News Feed}

All Latest news and activities stream from faculty are feed to user.

Faculty can inform announcements, news, activities to other users and other users can receive message from faculty easier.

News feed is necessary method to announce important news from faculty to other users. For example, alumni can be informed the date of reunion activity, current students will be notified for academic information, future student can access admission announcement, and firms are uttered for open house event.

\section{Photos}

All latest event photos are uploaded to social media and user can access them easier using mobile.

\section{E. Weather Forecast}

Weather forecast helps user to check the current weather at faculty.

Because of variability of the weather, students have to read the weather forecasting report before leaving home to prepare themselves. For instance, if it's raining, they should prepare for umbrella.

\section{F. Contact Us}

There are 3 methods to contact faculty which are e-mail, map, and phone.

Students, future students, alumni, or firm can send feedback to faculty or share the application to their friends via email service.

Map provides route travelling to CAMT using web mapping service. It helps in calculating the distance and time spent in traveling.

User can call directly to CAMT by press hotline button without dialing number.

\section{G. CAMT TUBE}

CAMTTUBE is the video-sharing tool that employs the video-sharing service. Students' masterpieces will be posted in CAMTTUBE channel. It is the intermediary for student to share and promote their idea and firm to seek for future workers.

The video tutorials are provided as well. It supports selfstudy to students.

\section{H. CAMT Shop}

CAMT Shop is CAMT souvenir market where new arrival items designed by CAMT are sold. This is a good method to allow alumni in contributing for faculty. 


\section{BENEFITS}

Social Media for Education provides the following benefits:

1) Marketing tool that is used to promote curriculums for those who would like to study in this faculty. Academic information is available for future student including software engineering (SE), animation (ANI), modern management and information technology (MMIT), and knowledge management (KM) that covering philosophy, curriculum structure, qualification of apply and requirement for admission, fee, career opportunities, and student activities.

2) To be the Communication channel for faculty, alumni, student, and future student. Faculty can send information including news, event, and activity to students, future students, alumni, and firms and they can send feedback to faculty as well.

3) To gather scattered social media altogether in order to support interaction and facilitate users such as official site, video-sharing website, social network service, and e-mail service.

4) To be an idea market where students present their contribution and firms seek for outstanding workers. To do so, employment opportunities for students is increased.

5) To promote self-study to students by providing video tutorial on CAMTTUBE. It is easy access via mobile. Students can study whenever they want and wherever they are.

\section{CONCLUSION}

This research discusses the social media for education on mobile using a case Study of College of Arts, Media and Technology, Thailand. This paper describes the proposed model and implemented prototype on mobile. The system consists of 5 subsystems based on user including future students, students, alumni, college, and firm. It integrates several social media to facilitate user in communication and education. The implemented prototype evinces a number of significant benefits and solves some issues to case study. For instance, it is the marketing tool used to announce all courses of faculty i.e. Software Engineering, Animation, Modern Management and Information Technology, and Knowledge Management. More over it is the communication hub that gathers all communication media together such as social network, video-sharing, email service, news feed and etc. in order to facilitate user interaction. It simulates the idea market using video-sharing service to increase the employment chance to students as well. The idea market is where student can sell their works to firms and firms look for future worker. It also supports student self-study by sharing video tutorial on mobile.

Future research will study on deploying cloud computing concept for student management system on mobile and expand to other mobile operating system as well.

\section{ACKNOWLEDGMENT}

This paper could not been possible without the continued effort and support of many people. The author wishes to thank Asst. Prof. Dr. Nopasit Chakpitak for invaluable assistance. Special thanks also to Mr. Nat Chantasingh, Miss Sumitra Kantawong, Dr. Noppon Choosri, Miss Parichat Phithakpraphanon, and Miss Wapee Manopiniwes for their encourage, advice and guidance. Without whose support this research could not be a reality.

\section{REFERENCES}

[1] S. Bennett. (June 25, 2012). Twitter, Facebook, Google, YouTube What Happens On The Internet Every 60 Seconds? [Online] Available: http://www.mediabistro.com/alltwitter/data-neversleeps_b24551

[2] Facebook Statistics by Country. [Online]. Available: http://www.socialbakers.com/

[3] Video Sharing. [Online]. Available: http://socialnetworking.swsi.wikispaces.net/VideoSharing

[4] Schlicht Patricia. (Oct 29, 2012). Using Social Media in Education (and Statistics). [Online]. Available: http://www.slideshare.net/pschlicht/using-social-media-in-educationand-statistics

[5] N. Winchester. (Aug 01, 2008). What is Social Media? [Online]. Available: http://www.icrossing.co.uk/fileadmin/uploads/eBooks/What_is_Socia 1_Media_iCrossing_ebook.pdf

[6] What is Social Networking? [Online]. Available: http://socialnetworking.swsi.wikispaces.net/SocialNetworking_what\# Anchor1

[7] H. Richmond. (Mar 21, 2011). The Growth of Mobile Marketing and

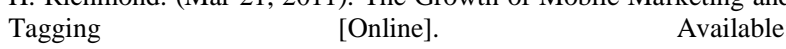
http://tag.microsoft.com/community/blog/t/the_growth_of_mobile_m arketing_and_tagging.aspx

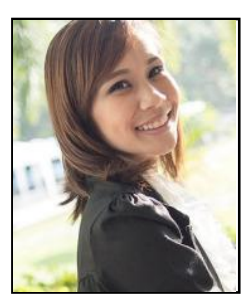

Jenjira Jaimunk is a teaching assistant in the Department of Software Engineering, College of Arts, Media and Technology, Chiang Mai University (CMU). She graduated from CMU with a Bachelor of Science program in software engineering in 2007. Right now, she is studying in the master program of Software Engineering at the same faculty.

Her research interests include a wide range of engineering principles, covering the methodology of software engineering, software process improvement, requirement engineering, software project management, social media on mobile device, and mobile computing.

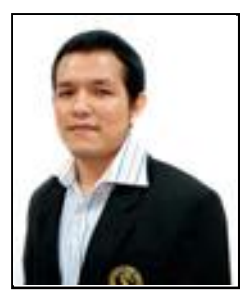

Pradorn Sureephong received his joint $\mathrm{PhD}$ degree in knowledge management (Thailand) and computer science (France). He is currently the director of Knowledge and Innovation Center (KIC) at Chiang Mai University. He also served as chair of master degree program committee in software engineering at College of Arts, Media and Technology (CAMT). $\mathrm{He}$ is presently a visiting professor of University of Lumiere Lyon 2 (France). His research interest focuses on the application of the knowledge management using information technology in various domains e.g. business, education, tourism. 